\title{
Application of a rhomboid flap for the coverage of defects after malignant breast tumor resection: A case report
}

\author{
KAZUYUKI KUBO ${ }^{1}$, HIROYUKI TAKEI ${ }^{2}$, HIROSHI MATSUMOTO ${ }^{1}$ and ATSUMORI HAMAHATA ${ }^{3}$ \\ ${ }^{1}$ Division of Breast Surgery, Saitama Cancer Center, Saitama 362-0806; \\ ${ }^{2}$ Department of Breast Oncology, Nippon Medical School, Tokyo 113-8603; \\ ${ }^{3}$ Division of Plastic and Reconstructive Surgery, Saitama Cancer Center, Saitama 362-0806, Japan
}

Received December 19, 2015; Accepted April 7, 2017

DOI: $10.3892 / \mathrm{ol} .2017 .6411$

\begin{abstract}
Resection for locally advanced breast cancer (LABC) or malignant phyllodes tumors may cause a large skin defect with bone exposure. Although skin grafts are frequently used to cover such defects, they can result in poor cosmetic outcomes and graft acceptance is dependent upon the condition of the recipient site. To overcome the limitations of skin grafts, various flaps have been developed to cover such defects. The present study used a rhomboid flap for the coverage of skin defects after mastectomy and breast-conservative surgery (BCS). A total of 11 patients with malignant breast cancer underwent reconstructive surgery using the rhomboid flap between September 2011 and December 2013 (mastectomy, 9 patients; BCS, 2 patients). Skin resection size, axillary lymph node dissection, bone exposure, length of surgery, wound complications and whether preoperative/postoperative adjuvant therapy was received were analyzed. The maximum size of skin defect covered with the rhomboid flap in the present study was $20 \times 20 \mathrm{~cm}$. There were no major wound complications and all patients underwent postoperative adjuvant therapy on schedule. During BCS, a portion of the flap was used for augmentation of the breast, in addition to coverage of the skin defect, which resulted in good cosmetic outcomes. The rhomboid flap can be quickly and easily fashioned, and it does not require any special instruments.
\end{abstract}

\section{Introduction}

Mastectomy for the treatment of locally advanced breast cancer (LABC) may cause large skin defects that cannot be closed directly. Even if the defect were closed directly using over-tension, the blood circulation to the edge of the skin would

Correspondence to: Dr Kazuyuki Kubo, Division of Breast Surgery, Saitama Cancer Center, 818 Komuro, Ina, Kita-Adachi, Saitama 362-0806, Japan

E-mail:kazu-k@cancer-c.pref.saitama.jp

Key words: breast cancer, malignant phyllodes tumor, surgical flap, rhomboid flap, reconstructive surgery be disturbed and prevent wound healing (1). Similar difficulties are observed in cases of mastectomy for the treatment of malignant phyllodes tumors, which invade a wide are of the skin and may cause the sternum or rib to be exposed. Skin grafting is the primary treatment for coverage of these types of skin defects. However, skin grafting has a poor aesthetic outcome and is not well received at cortical bone sites $(2,3)$. To overcome these limitations, various flaps have been developed, including myocutaneous, fasciocutaneous and cutaneous flaps (2,4-7).

Breast-conserving surgery (BCS) for LABC causes a relatively large skin defect. If the skin is closed directly, breast deformity or dislocation of the nipple-areolar complex may occur (8). Oncoplastic surgical techniques are necessary to achieve good cosmetic outcomes from BCS $(8,9)$.

The current study reports the application of a rhomboid flap for the coverage of skin defects after mastectomy or BCS in 11 female patients, which achieved good outcomes. The total number of surgeries for primary and recurrent breast cancer and malignant phyllodes tumor was 400-500/year at Saitama Cancer Center. Among them, 3-4 cases required rhomboid flap coverage. This method improved the patients' quality of life, as it enabled short surgery duration and hospital stays, efficient wound repair, and allowed for adjuvant therapy administration without delay. This present case report details the methods and describes the outcomes of the application of this technique.

\section{Case report}

\section{Materials and methods}

Patients. Between September 2011 and December 2013, reconstructive operations using a rhomboid flap were performed in 11 female patients who underwent mastectomy or BCS including skin resection, at Saitama Cancer Center (Saitama, Japan). The current study was approved by the Ethics Committee of Saitama Cancer Center and all patients provided written informed consent. The patients were aged 41-82 years old. A total of $9 / 11$ patients underwent mastectomy and 2/11 patients underwent BCS including skin resection. Out of the 9 patients who underwent a mastectomy, 6/9 were diagnosed with LABC, 2/9 were diagnosed with a malignant phyllodes tumor, and 1/9 was diagnosed with ipsilateral breast cancer recurrence with 


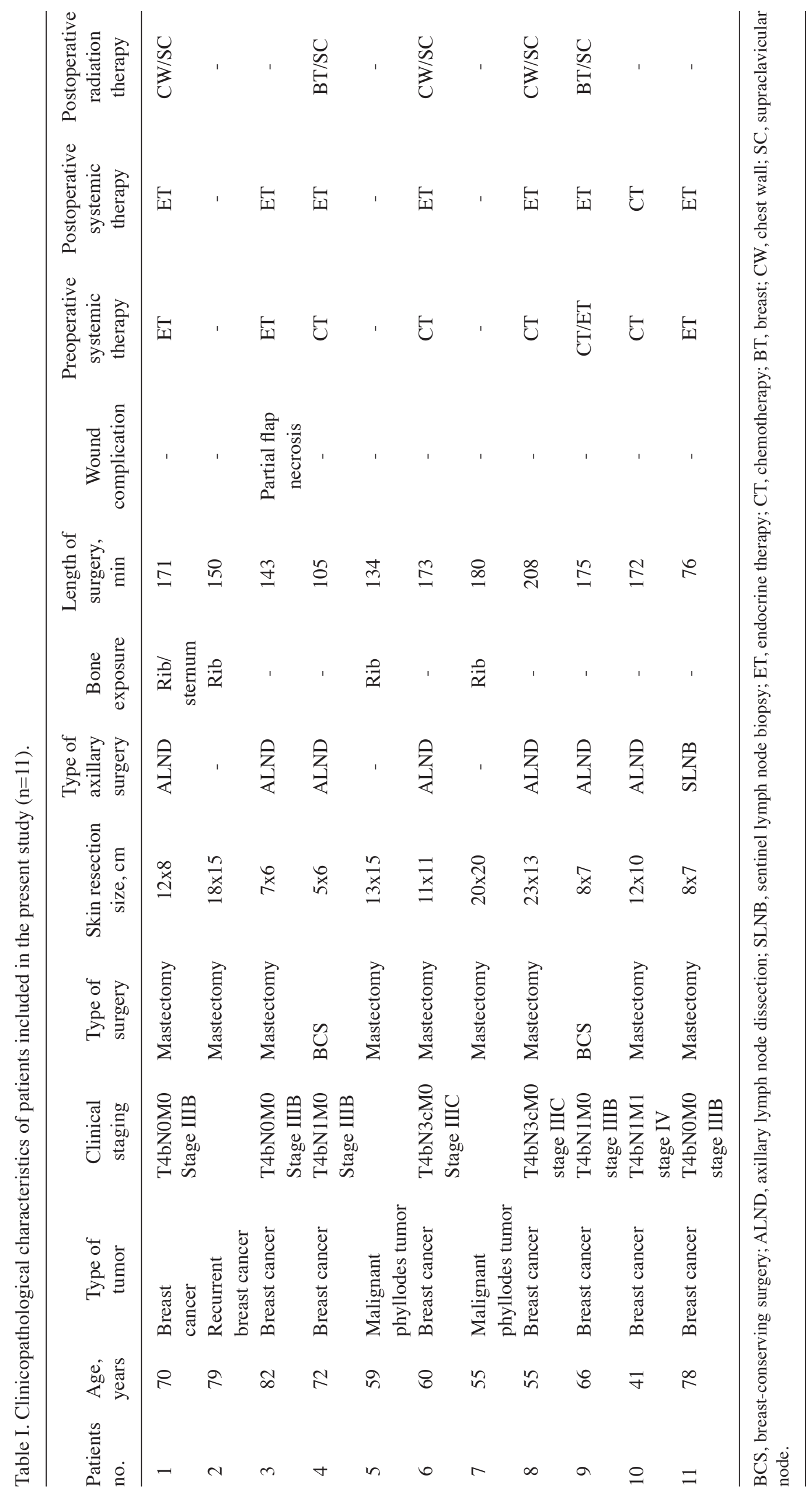


A

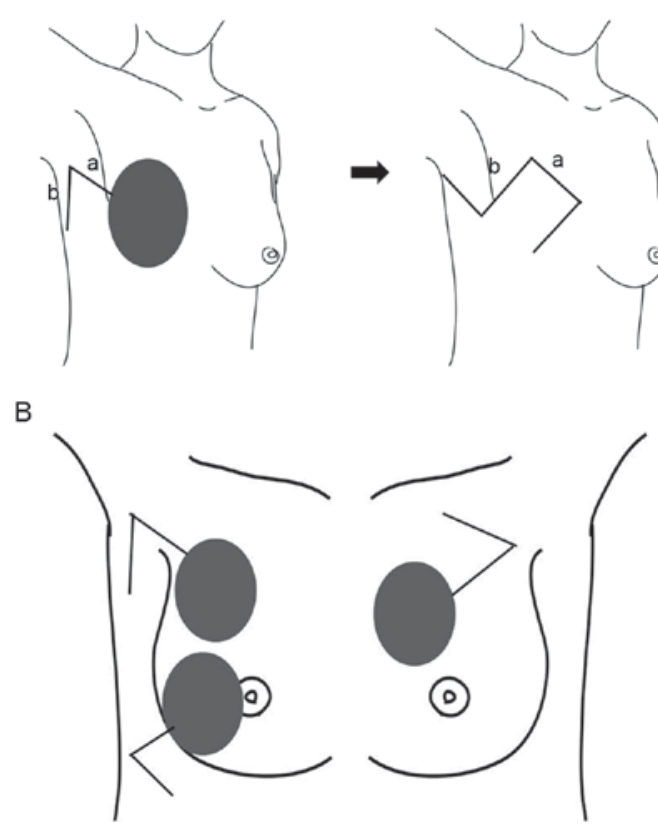

Figure 1. Schema of rhomboid flap designs for coverage of (A) mastectomy and (B) BCS defects.

an inflammation of the skin. The 2 patients who underwent BCS including skin resection were diagnosed with LABC. All patients with primary LABC had noninflammatory skin invasion [T4b; Union for International Cancer Control tumor-node-metastasis classification (10)] and an advanced tumor stage [stage IIIb/IIIc/IV (10)]. Although 2 patients had distant metastases, (both underwent mastectomy, one patient was diagnosed with LABC and the other was diagnosed malignant phyllodes tumor), they were in generally in good health and considered to be suitable candidates for surgery. No patients had any severe comorbidity, including diabetes, heart failure or asthma, and all patients were non-smokers. After the surgery, the size of the skin defect, the total surgery time and complication rate were analyzed. The clinicopathological characteristics, surgical data, and preoperative and postoperative treatment of the patients are presented in Table I.

Surgical technique. All surgery was performed under general anesthesia (desflurane inhalation 3\%, remifentanil i.v. $0.25 \mu \mathrm{g} / \mathrm{kg} / \mathrm{min}$, rocuronium i.v. $0.7 \mu \mathrm{g} / \mathrm{kg} / \mathrm{min}$ ) in a supine position. In the case of mastectomy, a resection line was marked on the skin and the tumor was resected. When axillary lymph node dissection was required, another incision line was drawn from the edge of resection area towards the axilla (line a; Fig. 1A). After completing the mastectomy with or without axillary lymph node dissection, another incision was made to create a rhomboid flap at the lateral side of the chest, and the flap was elevated (line b; Fig. 1A). By extending the length of the incision, the size of the flap can be changed to fit the size of the skin defect. Skin defects typically become slightly larger compared with the marked incision line prior to tumor resection, because the skin contracture caused by tumor invasion is released after tumor resection. Therefore, the size of flap should be estimated after tumor resection.
In the case of BCS, the location and design of the flap is dependent on the location of the skin defect (Fig. 1B). If the skin defect is located within the inner upper quadrant of the breast, the flap should be fashioned towards the outer lateral side of the skin defect. If the defect is located within the outer upper or outer lower quadrant of the breast, the flap should be made laterally to the defect. However, it is difficult to apply this flap for defects located within the inner lower quadrant.

When a rhomboid flap is designed with a superior pedicle within the axilla area, a dog-ear deformity is formed within the axilla area, which is difficult to revise during the surgery. When a rhomboid flap is designed with an inferior pedicle within the axilla area, an easily revised dog-ear deformity is formed at the front of the chest (Fig. 1A). If suitable perforator vessels from intercostal artery are identified during the flap elevation, they can be included to improve blood circulation to the flap.

Overall results. The overall results of the surgery are presented in Table I. The range in size of the skin defect was between $5 \times 6$ and $20 \times 20 \mathrm{~cm}$. A total of 7 patients underwent axillary lymph node dissection and 4 patients had bone exposure during the surgery (costal bone, 3 patients; costal bone and sternal bone, 1 patient). The length of time of the surgery ranged from 76-208 min (average time, $153.4 \mathrm{~min}$ ). No wound complications from the surgical procedures were recorded. Partial necrosis was observed at the distant parts of the flap in 1 patient, which healed quickly with debridement and application of an oil base ointment. A total of 8 patients underwent preoperative systemic therapy (chemotherapy, 4 patients; endocrine therapy, 3 patients; chemotherapy and endocrine therapy, 1 patient). No patients had received preoperative radiation therapy. Postoperative systemic therapy was received by 8 patients (endocrine therapy, 7 patients; chemotherapy, 1 patient). A total of 5 patients underwent postoperative radiation therapy (chest wall and supraclavicular node, 3 patients; breast and supraclavicular node, 2 patients).

\section{Representative cases}

Case 1 (patient 7). A 55-year-old woman was diagnosed with a malignant phyllodes tumor at the Saitama Cancer Center (Table I). The patient first noticed a tumor in their left breast several years prior to presenting, which had rapidly increased in size in the last several months. The maximum diameter of the tumor was $30 \mathrm{~cm}$ and the affected breast had an ulcer that oozed continuously (Fig. 2A). No distant metastases were detected in preoperative examinations. A mastectomy with axillary lymph node dissection was performed under general anesthesia in the supine position. As a result, a 20x20 cm skin defect and costal bone exposure occurred after the tumor resection (Fig. 2B; Table I). A rhomboid flap with an inferior pedicle $(15 \mathrm{~cm}$ limbs) was fashioned towards the lateral side of the skin defect (Fig. 2C). The flap covered the defect and the wound healed completely with no complications, and there was no sign of local recurrence or metastasis 4 months after surgery (Fig. 2D).

Case 2 (patient 9). A 66-year-old woman was diagnosed with LABC (T4cN1M0 stage IIIB) after presenting to the Saitama 
A

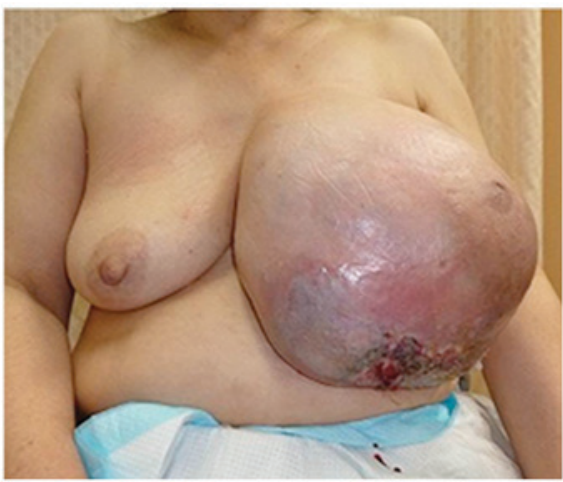

$\mathrm{C}$

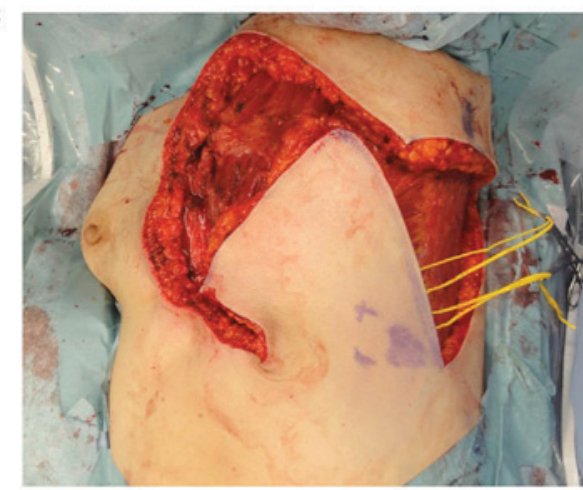

B

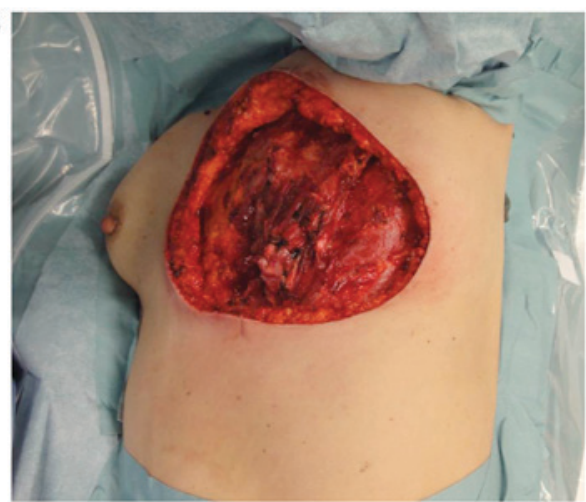

D

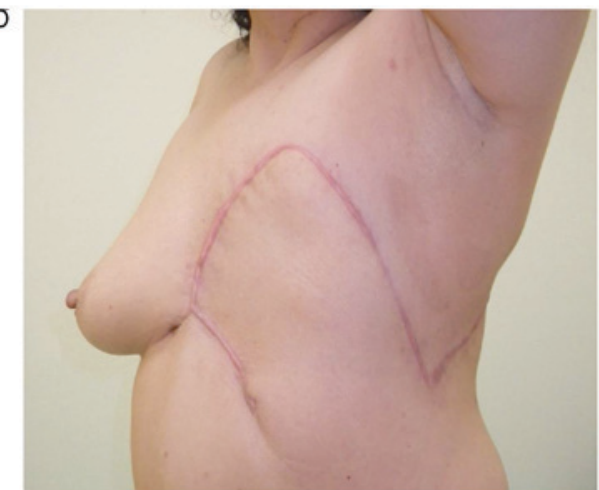

Figure 2. Preoperative and postoperative views of case 1 (patient 7). (A) Preoperatively, the tumor had a maximum diameter of $30 \mathrm{~cm}$ with a continuously bleeding skin ulcer (A). (B) The skin defect after tumor resection, in which the costal bones were exposed. (C) The rhomboid flap fashioned after transposition. (D) The outcome 8 months after surgery.
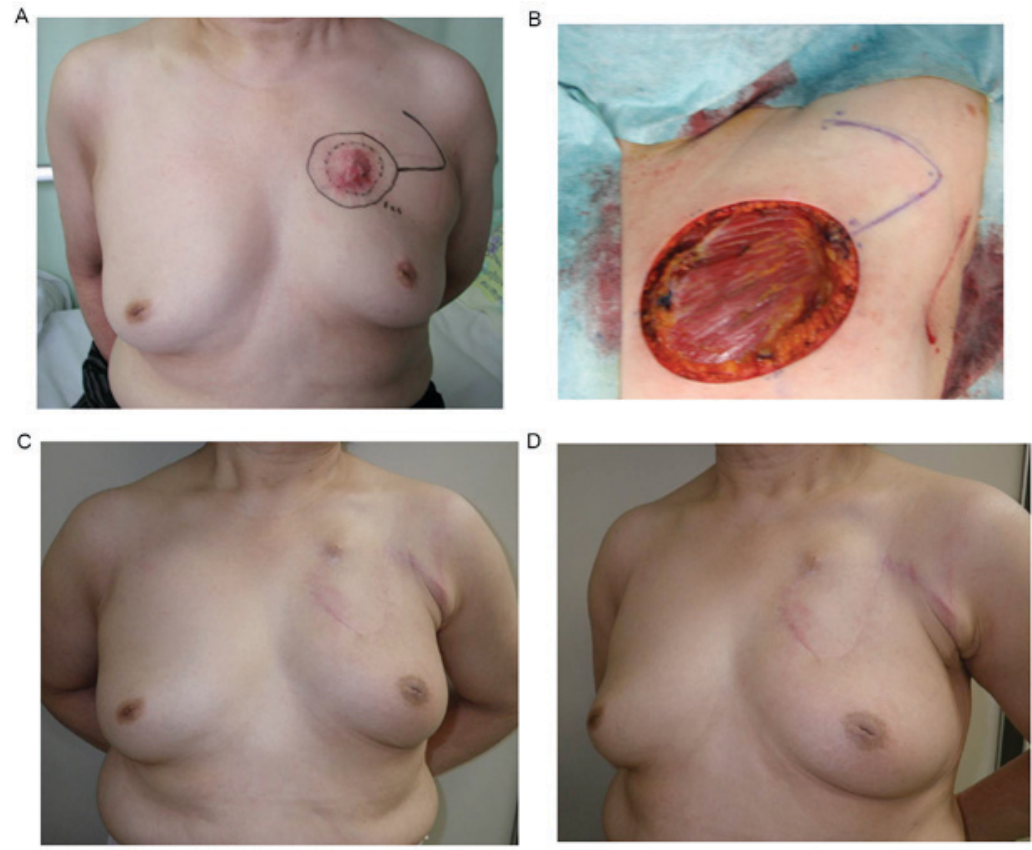

Figure 3. Preoperative and postoperative views of case 2 (patient 9). (A) Preoperative view of the tumor and resection markings. The nipple-areolar complex of the left breast was raised compared with that of the right breast due to the tumor. (B) The skin defect after tumor resection. (C and D) A total of 8 months after surgery the breasts were almost symmetrical.

Cancer Center (Table I). The patient underwent preoperative systemic therapy $\left(4\right.$ cycles triweekly doxorubicin $60 \mathrm{mg} / \mathrm{m}^{2}$ cyclophosphamide $600 \mathrm{mg} / \mathrm{m}^{2}$ followed by 4 cycles triweekly docetaxel $75 \mathrm{mg} / \mathrm{m}^{2}$ followed by 6 months aromatase inhibitor administration), to which the tumor exhibited a partial response. A BCS including skin resection and axillary lymph node dissection was performed. Due to the contracture caused by the invasion of the tumor, the left side nipple-areolar complex 
was located superior with respect to the right side (Fig. 3A). The size of skin resection was $8 \times 7 \mathrm{~cm}$. A rhomboid flap with $7 \mathrm{~cm}$ limbs was fashioned towards the lateral side of the skin defect within the axilla, revealing deep fascia of pectralis major muscle (Fig. 3B). The flap was elevated and the skin defect was covered with the flap. Pathological examination, performed as previously described (11), revealed ypT4bN0 invasive ductal carcinoma with positive estrogen receptor, positive progesterone receptor and negative human epidermal growth factor receptor 2 status (data not shown). The patient underwent postoperative endocrine therapy and breast/supraclavicular node radiation therapy. A total of 8 months after surgery there was no sign of locoregional recurrence or metastasis. The malposition of the nipple-areolar complex was corrected and the breasts were almost symmetrical (Fig. 3C and D).

\section{Discussion}

There are regional differences in the incidence of LABC due to accessibility to medical services (12). Due to advancements in systemic therapy, the extent of surgical treatment required for LABC has decreased (13). The volume of LABC tumors can typically be decreased preoperatively with neoadjuvant systemic therapy, which has a high response rate $(13,14)$. However, certain cases require a large-scale resection, producing a large skin defect (15). The majority of phyllodes tumors are benign and only a small number of cases are diagnosed as malignant, characterized by a marked proliferation of the stromal cells and metastatic potential (16). It is rare for flap coverage to be required for skin defects after the resection of malignant phyllodes tumors. However, if the tumor invades the surrounding tissues an extended tumor resection is required $(17,18)$.

Skin grafting is a useful technique in the correction of skin defects; however, they have several disadvantages, including the following: Cosmetic morbidities caused by a mismatched color and/or texture of the grafted skin; scar contracture due to thinner skin; and a poor response to grafting, which is dependent on the condition of the recipient site. A number of flap coverage techniques for skin defects after breast surgery have been reported $(2,4-7)$. Pedicled myocutaneous flaps, including latissimus dorsi, external oblique and rectus abdominis myocutaneous flaps, can cover large skin defects with a stable blood flow, so they have been considered useful methods. The application of cutaneous or fasciocutaneous flaps, including any local flap, is another useful method as they do not require the sacrifice of major muscles.

Although various methods of flap coverage have been reported, there are few comparative studies between these methods. Deo et al (19) reported that fasciocutaneous flaps are more successful compared with myocutaneous flap due to decreased blood loss during the surgery, a shorter length of the surgery and a shorter hospital stay. Conversely, Martella et al (20) suggested that there is no difference between myocutaneous and fasciocutaneous flaps in regards to local complications and the length of hospital stay required. Typically, myocutaneous flaps provide enough tissue volume to cover the skin defect and have a good blood supply $(2,21)$. Cutaneous and fasciocutaneous flaps do not require the loss of major muscles and can be completed in a shorter length of time (19). The flap method should be considered and chosen on a case-by-cases basis according to the size of the skin defect and the condition of the recipient/donor sites.

The rhomboid flap, a type of transposition flap, has been frequently used for $>50$ years since Dr Limberg's first reports (22), and variable modified methods have been reported (23-25). The present study applied the rhomboid flap for coverage of skin defects in patients with LABC or malignant phyllodes tumors after mastectomy or BCS including skin resection, and achieved good outcomes. The rhomboid flap can be elevated as a cutaneous or fasciocutaneous flap, and the blood circulation to the flap is very stable $(26,27)$. The maximum skin defect size that can be covered with the rhomboid flap depends on the flexibility of the skin and the amount of subcutaneous fat tissue in the individual (28). A maximum skin defect size of $20 \times 20 \mathrm{~cm}$ was covered with the rhomboid flap in the present study.

Due to advancements in neoadjuvant systemic therapy for LABC, it is possible for patients with LABC to undergo $\mathrm{BCS}$. Touboul et al (29) reported that BCS is not inferior compared with mastectomy for the treatment of LABC after chemotherapy in regards to overall survival rates if residual tumor sizes were small. However, the optimal local management for patients with LABC remains undefined (14,29-31). This warrant further study, particularly following recent advancements in systemic therapy. For patients with LABC, oncoplastic breast surgery is frequently required for cosmetic reasons, in addition to wound management, due to the large amount of skin and soft tissue resection in the majority of cases. Only a few studies have investigated the safety of BCS with oncoplastic surgery compared with BCS without oncoplastic surgery in patients with LABC $(32,33)$, so additional research in this area is required.

Methods of BCS are classified into two groups as follows: Volume displacement using glandular transposition and volume replacement using autologous tissue $(9,34,35)$. The method applied should be chosen based on the size of the defect and the breast. The volume replacement technique, which includes the rhomboid flap, is useful for large defects and small breast sizes (9).

In conclusion, the rhomboid flap can be fashioned quickly and easily, with a low risk of flap failure. The flap can cover a relatively large skin defect, provide soft tissue volume and achieve good cosmetic results. In addition, no special devices are required to harvest the flap. Therefore, it is a good method for the coverage of defects after malignant breast tumor resection.

\section{Acknowledgements}

The authors would like to thank Dr Jeffrey D. Meserve (The University of Texas, TX, USA) for his editorial assistance.

\section{References}

1. Robertson SA, Jeevaratnam JA, Agrawal A and Cutress RI: Mastectomy skin flap necrosis: Challenges and solutions. Breast Cancer (Dove Med Press) 9: 141-152, 2017.

2. Persichetti P, Tenna S, Cagli B and Scuderi N: Extended cutaneous 'thoracoabdominal' flap for large chest wall reconstruction. Ann Plast Surg 57: 177-183, 2006. 
3. Mathes SJ: Mathes plastic surgery. Saunders Elsevier, Philadelphia, 293-316, 2006.

4. Arnold PG and Pairolero PC: Chest-wall reconstruction: An account of 500 consecutive patients. Plast Reconstr Surg 98: 804-810, 1996

5. Bogossian N, Chaglassian T, Rosenberg PH and Moore MP: External oblique myocutaneous flap coverage of large chest-wall defects following resection of breast tumors. Plast Reconstr Surg 97: 97-103, 1996

6. Larson DL and McMurtrey MJ: Musculocutaneous flap reconstruction of chest-wall defects: An experience with 50 patients. Plast Reconstr Surg 73: 734-740, 1984.

7. Woo E, Tan BK, Koong HN, Yeo A, Chan MY and Song C: Use of the extended V-Y latissimus dorsi myocutaneous flap for chest wall reconstruction in locally advanced breast cancer. Ann Thorac Surg 82: 752-755, 2006.

8. Emiroglu M, Sert I, Karaali C, Aksoy SO, Ugurlu L and Aydin C: The effectiveness of simultaneous oncoplastic breast surgery in patients with locally advanced breast cancer. Breast Cancer 23 463-470, 2016.

9. Haloua MH, Krekel NM, Winters HA, Rietveld DH, Meijer S, Bloemers FW and van den Tol MP: A systematic review of oncoplastic breast-conserving surgery: Current weaknesses and future prospects. Ann Surg 257: 609-620, 2013.

10. Sobin L, Gospodarowicz M and Wittekind C: TNM Classification of malignant tumours seventh edition. John Wiley \& Sons. Ltd, New Jersey, pp181-193, 2009.

11. Hoda SA, Brogi E, Koerner FC and Rosen PP: Rosen's Breast Pathology fourth edition. Lippincott Williams \& Wilkins, Philadelphia, pp413-467, 2014

12. Sinacki M, Badzio A, Wełnicka-Jaśkiewicz M, Bogaerts J, Piccart MJ, Therasse P, Smith IE, Hatschek T and Jassem J: Pattern of care in locally advanced breast cancer: Focus on local therapy. Breast 20: 145-150, 2011.

13. Eroglu A and Aydin F: Management of non-inflammatory locally advanced breast cancer: Focus on surgical approaches. Exp Oncol 35: 272-279, 2013.

14. Sinacki M, Jassem J and van Tienhoven G: Conservative local treatment versus mastectomy after induction chemotherapy in locally advanced breast cancer: A randomised phase III study (EORTC 10974/22002, LAMANOMA)-why did this study fail? Eur J Cancer 41: 2787-2788, 2005.

15. Arya R, Chow WT, Rozen WM, Patel NG, Griffiths M, Shah S and Ramakrishnan VV: Microsurgical reconstruction of large oncologic chest wall defects for locally advanced breast cancer or osteoradionecrosis: A retrospective review of 26 cases over a 5-year period. J Reconstr Microsurg 32: 121-127, 2016.

16. AP J: Phyllodes tumors. Diseases of the breast, 3rd edition, Lippincott Williams \& Wilkins, Philadelphia, pp669-675, 2000.

17. Rajesh A and Farooq M: Resection and reconstruction following recurrent malignant phyllodes-Case report and review of literature. Ann Med Surg (Lond) 16: 14-18, 2017.

18. Banno A, Shimada A, Aga K, Harada H, Kaburagi T, Seki H, Yasui $\mathrm{N}$ and Matsumoto $\mathrm{H}$ : Total mastectomy and chest reconstruction for a rapidly progressing giant phyllodes tumor with skin necrosis: A case report. Surg Case Rep 1: 82, 2015.

19. Deo SV, Purkayastha J, Shukla NK and Asthana S: Myocutaneous versus thoraco-abdominal flap cover for soft tissue defects following surgery for locally advanced and recurrent breast cancer. J Surg Oncol 83: 31-35, 2003.

20. Martella S, Caliskan M, Brenelli FP, Rossetto F, Aparecida De Oliveira H, De Brito Lima LN, Chifu C, Rodriguez-Fernandez J, Petit JY and Luini A: Surgical closure of chest wall in noninflammatory locally advanced breast carcinoma with ulceration of the skin. Breast J 14: 345-352, 2008.
21. Pavletic MM, Kostolich M, Koblik P and Engler S: A comparison of the cutaneous trunci myocutaneous flap and latissimus dorsi myocutaneous flap in the dog. Vet Surg 16: 283-293, 1987.

22. Limberg A: Mathematical principles of local plastic procedures on the surface of the human body. Medgis, Leningrad, 1946.

23. Akin M, Leventoglu S, Mentes BB, Bostanci H, Gokbayir H, Kilic K, Ozdemir E and Ferahkose Z: Comparison of the classic Limberg flap and modified Limberg flap in the treatment of pilonidal sinus disease: A retrospective analysis of 416 patients. Surg Today 40: 757-762, 2010.

24. Quaba AA and Sommerlad BC: 'A square peg into a round hole': A modified rhomboid flap and its clinical application. Br J Plast Surg 40: 163-170, 1987.

25. Yucel E, Tezcan L, Yilmaz OC and Akin ML: 'Flag Excision and Flap' Procedure: A novel modification for off-midline closure after pilonidal sinus excision. Indian J Surg 77 (Suppl 3): S1191-S1195, 2015

26. Azab AS, Kamal MS and el Bassyoni F: The rationale of using the rhomboid fasciocutaneous transposition flap for the radical cure of pilonidal sinus. J Dermatol Surg Oncol 12: 1295-1299, 1986.

27. Blake BP, Simonetta CJ and Maher IA: Transposition flaps: Principles and locations. Dermatol Surg 41 (Suppl 10): S255-S264, 2015.

28. Thorne CH: Grabb \& Smith's Plastic Surgery 6th edition. Lippincott Williams \& Wilkins, Philadelphia, pp12, 2007.

29. Touboul E, Buffat L, Lefranc JP, Blondon J, Deniaud E, Mammar H, Laugier A and Schlienger M: Possibility of conservative local treatment after combined chemotherapy and preoperative irradiation for locally advanced noninflammatory breast cancer. Int J Radiat Oncol Biol Phys 34: 1019-1028, 1996.

30. De Lena M, Varini M, Zucali R, Rovini D, Viganotti G, Valagussa P, Veronesi U and Bonadonna G: Multimodal treatment for locally advanced breast cancer. Result of chemotherapy-radiotherapy versus chemotherapy-surgery. Cancer Clin Trials 4: 229-236, 1981.

31. Perloff M, Lesnick GJ, Korzun A, Chu F, Holland JF, Thirlwell MP, Ellison RR, Carey RW, Leone L, Weinberg V, et al: Combination chemotherapy with mastectomy or radiotherapy for stage III breast carcinoma: A Cancer and Leukemia Group B study. J Clin Oncol 6: 261-269, 1988.

32. Chauhan A, Sharma MM and Kumar K: Evaluation of surgical outcomes of oncoplasty breast surgery in locally advanced breast cancer and comparison with conventional breast conservation surgery. Indian J Surg Oncol 7: 413-419, 2016.

33. Silverstein MJ, Savalia N, Khan S and Ryan J: Extreme oncoplasty: Breast conservation for patients who need mastectomy. Breast J 21: 52-59, 2015

34. Giacalone PL, Roger P, Dubon O, El Gareh N, Rihaoui S, Taourel P and Daurés JP: Comparative study of the accuracy of breast resection in oncoplastic surgery and quadrantectomy in breast cancer. Ann Surg Oncol 14: 605-614, 2007.

35. Kaur N, Petit JY, Rietjens M, Maffini F, Luini A, Gatti G, Rey PC, Urban C and De Lorenzi F: Comparative study of surgical margins in oncoplastic surgery and quadrantectomy in breast cancer. Ann Surg Oncol 12: 539-545, 2005. 